\title{
Reversible MRI Findings in a Case of Migraine with Brainstem Aura
}

\author{
Bir Beyin Sapı Auralı Migren Olgusunda Geçici MRG Bulguları
}

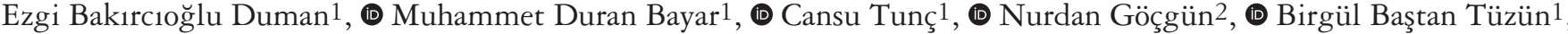 \\ (1) Ayşe Özlem Çokar ${ }^{1}$
}

1 University of Health Sciences Turkey, Haseki Training and Research Hospital, Clinic of Neurology, Istanbul, Turkey 2University of Health Sciences Turkey, Haseki Training and Research Hospital, Clinic of Radiology, Istanbul, Turkey

Keywords: Migraine, migraine with brainstem aura, diffusion restriction

Anahtar Kelimeler: Migren, beyin sapı auralı migren, diffüzyon kısıtlılığ 1

\section{Dear Editor,}

A 29-year-old woman was admitted to the emergency department with speech impairment. The patient reported vertigo, visual impairment in the right side of the visual field, and a tingling sensation in the left arm that lasted 15 minutes, accompanied by slurred speech and bilateral frontal headache with a throbbing quality. During the neurologic assessment, the headache, which lasted 2 hours, was treated with symptomatic treatment, but ataxic dysarthria persisted. The patient had already been diagnosed as having migraine with aura. Her previous headaches were unilateral, accompanied by photophobia and phonophobia, lasting 24 hours without medication. She had experienced slight tingling in the arm, but never slurred speech. Her medical history revealed the use of oral contraceptives and naproxen tablets. Neurologic examination showed only severe ataxic dysarthria. The reported homonymous hemianopia lasted 15 minutes, so it was over by the time of the examination. Routine blood tests were normal. Brain computed tomography (CT) was unremarkable. Diffusionweighted imaging (DWI) and apparent diffusion coefficient (ADC) sequences of magnetic resonance imaging (MRI) of the brain showed mild, bilateral symmetric, diffusion restrictions in the cerebellar folia (Figure 1a, b) with hypointensity in a T1weighted image (WI), mild hyperintensity and swelling in T2WI, without any hemorrhage. Although diffusion restriction mimics stroke, CT angiography showed no pathologic findings. The stroke etiology became controversial because the neurologic symptoms regressed completely within a day. The complete regression of pathologic signals in the cerebellum without any hyperintensity of gliosis or encephalomalacia in the follow-up MRI, which was seen after 19 days (Figure 2a, b), ruled out the vascular etiology and indicated a transient systemic-metabolic disorder. With due consideration of the patient's history and clinical findings, the preliminary diagnosis was migraine with brainstem aura (MBA).

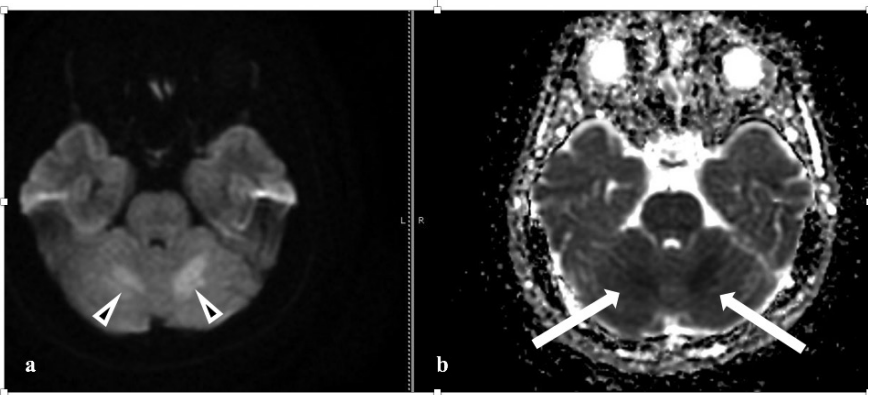

Figure 1. DWI (a) and ADC (b) MRI sequences. Bilateral symmetric, diffusion restrictions in cerebellar folia are observed. High signals (arrowheads) and low signals (arrows) are seen

DWI: Diffusion-weighted imaging, ADC: Apparent diffusion coefficient, MRI: Magnetic resonance imaging

Address for Correspondence/Yazışma Adresi: Ezgi Bakırcıŏlu Duman MD, University of Health Sciences Turkey, Haseki Training and Research Hospital, Clinic of Neurology, Istanbul, Turkey

Phone: +902124532000 E-mail: ezgibakircioglu@gmail.com ORCID: orcid.org/0000-0002-1912-8325 Received/Geliş Tarihi: 01.12.2020 Accepted/Kabul Tarihi: 23.04.2021 
Dysarthria regressed within 24 hours and follow-up MRI showed complete resolution of the described DWI/ADC restriction areas. Antiemetic and non-steroidal anti-inflammatory treatment was found sufficient in the follow-up. Informed consent was obtained from the patient for this case report.

MBA is a rare subtype of migraine with aura, which has diagnostic criteria defined by the International Classification of Headache Disorders-3 (1). Symptoms may vary, and exclusion of cerebrovascular disease, seizure, posterior fossa tumors, cerebral venous thrombosis, and other primary headaches is required. MBA is the third most common disorder that can mimic stroke, after seizures and psychiatric disorders, accounting for $18 \%$ of all patients admitted to emergency clinics with stroke-like symptoms (2). In the course of migraine attacks, transient neurologic dysfunctions and rarely abnormal findings in neuroimaging can be seen (3). Migrainous infarction, a rare complication of migraine, is seen predominantly in women; infarcts are mostly in the posterior circulation (4). Previous literature suggests cerebellar hypoperfusion as a potential cause of cerebellar infarct-like lesions in migraine with aura (5).

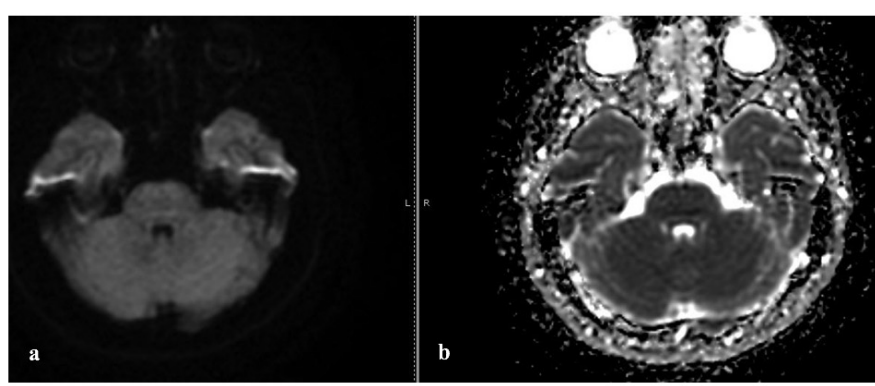

Figure 2. DWI (a) and ADC (b) MRI sequences. After 19 days, it was observed that the signals were completely regressed

DWI: Diffusion-weighted imaging, ADC: Apparent diffusion coefficient, MRI: Magnetic resonance imaging
Our patient with MBA was admitted with stroke-like symptoms and restricted diffusion. The differential diagnosis is crucial in patients presenting with stroke-like symptoms or restricted diffusion, which can also be seen in the postictal period, pyogenic abscess, demyelinating plaques, high-grade gliomas, migraine attacks, and other inflammatory lesions. It should be kept in mind that reversible restricted diffusion can rarely occur in MBA.

\section{Ethics}

Informed Consent: Informed consent was obtained from the patient for this case report.

Peer-review: Externally and internally peer-reviewed.

\section{Authorship Contributions}

Concept: A.Ö.Ç., B.B.T., Design: M.D.B., N.G., Data Collection or Processing: E.B.D., C.T., Analysis or Interpretation: C.T., N.G., Literature Search: E.B.D., B.B.T., Writing: E.B.D., C.T.

Conflict of Interest: No conflict of interest was declared by the authors.

Financial Disclosure: The authors declared that this study received no financial support.

\section{References}

1. ICHD-3. 1.2.2 Migraine with brainstem aura. International Classification of Headache Disorders 3rd, May 25, 2020. Available from: https://ichd-3. org/1-migraine/1-2-migraine-with-aura/1-2-2-migraine-with-brainstemaura/.

2. Terrin A, Toldo G, Ermani M, Mainardi F, Maggioni F. When migraine mimics stroke: a systematic review. Cephalalgia 2018;38:2068-2078.

3. Russo A, Silvestro M, Tessitore A, Tedeschi G. Advances in migraine neuroimaging and clinical utility: from the MRI to the bedside. Expert Rev Neurother 2018;18:533-544

4. Wolf ME, Szabo K, Griebe M, et al. Clinical and MRI characteristics of acute migrainous infarction. Neurology 2011;76:1911-1917.

5. Kruit MC. Migraine as a risk factor for subclinical brain lesions. JAMA 2004;291:427. 